\title{
High-precision finite element analysis of elastoplastic dynamic responses of super-high-rise steel frames
}

\section{AUTHOR(S):}

Ohsaki, Makoto; Miyamura, Tomoshi; Kohiyama, Masayuki; Hori, Muneo; Noguchi, Hirohisa; Akiba, Hiroshi; Kajiwara, Koichi; Ine, Tatsuhiko

\section{CITATION:}

Ohsaki, Makoto ...[et al]. High-precision finite element analysis of elastoplastic dynamic responses of super-high-rise steel frames. Earthquake Engineering \& Structural Dynamics 2009, 38(5): 635-654

\section{ISSUE DATE:}

2009-04-25

URL:

http://hdl.handle.net/2433/250757

\section{RIGHT:}

This is the peer reviewed version of the following article: Makoto Ohsaki, Tomoshi Miyamura, Masayuki Kohiyama, Muneo Hori, Hirohisa Noguchi, Hiroshi Akiba, Koichi Kajiwara, Tatsuhiko Ine (2009). High-precision finite element analysis of elastoplastic dynamic responses of super-high-rise steel frames. Earthquake Engineering \& Structural Dynamics, 38(5), 635-654, which has been published in final form at https://doi.org/10.1002/eqe.900. This article may be used for non-commercial purposes in accordance with Wiley Terms and Conditions for Use of Self-Archived Versions.: この論文は出版社版でありません。引用の際には出版社版をご確認ご利用ください。; This is not the published version. Please cite only the published version. 


\title{
High-precision finite element analysis of elastoplastic dynamic responses of super-highrise steel frames
}

\author{
Makoto Ohsaki ${ }^{1}$, Tomoshi Miyamura ${ }^{2}$, Masayuki Kohiyama ${ }^{3}$, Muneo Hori ${ }^{4}$, \\ Hirohisa Noguchi ${ }^{3}$, Hiroshi Akiba ${ }^{5}$, Koichi Kajiwara ${ }^{6}$, Tatsuhiko Ine ${ }^{6}$ \\ ${ }^{1}$ Department of Architecture and Architectural Engineering, Kyoto University, \\ Kyotodaigaku-Katsura, Nishikyo-ku, Kyoto 615-8540, Japan \\ ${ }^{2}$ Department of Computer Science, College of Engineering, Nihon University, \\ 1 Nakagawara, Tokusada, Tamura-machi, Koriyama 963-8642, Japan \\ ${ }^{3}$ Department of System Design Engineering, Keio University, \\ 3-14-1 Hiyoshi, Kohoku-ku, Yokohama 223-8522, Japan \\ ${ }^{4}$ Earthquake Research Institute, The University of Tokyo, \\ 1-1-1 Yayoi, Bunkyou-ku, Tokyo 113-0032, Japan \\ ${ }^{5}$ Allied Engineering, 1-14-4 Shiba, Minato-ku, Tokyo 105-0014, Japan \\ ${ }^{6}$ Hyogo Earthquake Eng. Res. Center, Natl. Res. Inst. for Earth Sci. and Disaster Prevention, \\ 1501-21 Nishikameyama, Mitsuta, Shijimi-cho, Miki 673-0515, Japan
}

\section{SUMMARY}

A new framework is presented for analysis of dynamic collapse behavior of steel frames using large-scale parallel finite element method based on the domain decomposition method. The analysis software is based on ADVC as a part of the E-Simulator that takes advantage of recent development of computer science and high-performance parallel computing in computational mechanics. By making an analysis model with fine meshing, a complicated sequence of local buckling of columns and beams can be simulated. Numerical results are shown for dynamic collapse analysis of single-story and 5-story frame models to show that the global and local behaviors are simultaneously simulated by a high-precision finite element analysis. Eigenvalue analysis is also carried out for a 31-story frame to demonstrate that dynamic analysis can be carried out for a structure discretized to solid elements with more than 70 million DOFs.

\section{Keywords}

large-scale structure, dynamic collapse analysis, finite element analysis, E-Simulator, steel frame

\section{INTRODUCTION}

The most conventional approach to design of a highrise steel frame is based on pushover analysis to construct a lumped mass model with multi-linear shear-drift relations of the stories, followed by elastoplastic time-history analysis for the lumped mass model. The deformation demands for members and connections are obtained from the maximum deformation of the lumped mass model under design seismic excitations corresponding to various performance levels. The plastic deformation of member ends and connections of the three-dimensional frame model for pushover analysis is obtained using empirically defined hinge or fiber model. Therefore, the seismic responses computed using the lumped mass model strongly depend on the assumption and intuition made by a designer. Furthermore, three-dimensional torsional responses, if exist, cannot be accurately simulated through this two-step procedure. 
The project of E-Simulator is under way at Hyogo Earthquake Engineering Research Center (E-Defense) that facilitates the world's largest shaking table [1,2]. The E-Simulator uses ADVC as a platform. ADVC is a commercial finite element package that is specially tuned for computation on 64-bit architecture CPUs, and uses domain decomposition technique for parallel implementation. It can solve dynamic nonlinear problems with more than 10 million DOFs for a structure discretized by three-dimensional solid elements. The E-Simulator is conceived as a virtual shaking-table, and its final form is a software environment to simulate global and local seismic responses of a city, as assemblage of buildings and infrastructures, by fully taking advantage of recent development of computer science and high-performance computing in computational mechanics. As a part of this project, the purpose of this paper is to show that the global and local behaviors of a steel frame under severe seismic motions can be simultaneously simulated by a high-precision Finite Element (FE) analysis software.

It has been shown in the previous studies that the collapse behavior of small steel frames can be simulated within moderately good accuracy by an FE-analysis with shell elements $[3,4]$. Charmpis and Papadrakakis [5] investigated applicability of high-performance computing to various types of structures including a three-dimensional frame. Challa and Hall [6] used a fiber model and a panel zone model that can simulate the realistic degrading behavior, and carried out dynamic collapse analysis of a 20 -story plane frame.

The tragic event of the World Trade Center in 2001 initiated the studies on progressive collapse analysis of steel frames. Isobe and Lynn [7], and Lynn and Isobe [8] carried out dynamic collapse analysis of a super-highrise frame against impact loads using the ASI-Gauss method. However, their method is basically an extension of a beam-column model, and the total number of DOFs in their example is less than 300,000. Kaewkulchai and Williamson [9] presented a damage-dependent generalized plastic hinge model, and developed a method for simulating redistribution of internal forces for small-scale frames. Khandelwal et al. [10] presented a simple method of removing fractured members, and demonstrated through analysis of plane braced frames that an eccentrically braced frame is less vulnerable to progressive collapse than a concentrically braced frame. The recent developments of collapse analysis can be found in the review paper by Villaverde [11]. However, there is no study on large-scale collapse analysis of a three-dimensional frame discretized to solid elements with more than 10 million DOFs.

FE-analysis has also been effectively used for simulating the elastoplastic responses of structural parts such as beam-to-column connections and column bases [12]. Pan et al. [13] optimized the flange shape of the Reduced Beam Section (RBS) to show that FE-analysis can replace the role of physical tests for development of a new type of structural part by structural optimization. The effectiveness of a new structural system, such as self-centering connection [14], can be verified by a high-precision FE-analysis of the whole structure, which cannot be done by a physical test.

In this paper, a general-purpose parallel FE-analysis software based on the domain decomposition method, which is a platform of the E-Simulator, is applied to simulation of dynamic responses of large-scale steel frames. Numerical results are shown for dynamic collapse analysis of single-story and 5-story frame models to demonstrate that the global and local behaviors are simultaneously simulated by a high-precision FE-analysis. Eigenvalue analysis is also carried out for a 31-story frame to demonstrate applicability of FE-analysis to a structure with more than 70 million DOFs.

\section{DESCRIPTION OF 31-STORY SUPER-HIGHRISE STEEL FRAME MODEL}

A 31-story steel building frame as shown in Fig. 1 has been designed as a specimen of the 
E-simulator. The frame is a center-core-type 31-story office building. The story height is 5.4 $\mathrm{m}$ for $1 \mathrm{st}$ and $2 \mathrm{nd}$ stories, and $4.1 \mathrm{~m}$ for the other stories. The total height is $129.7 \mathrm{~m}$, and the size of the plan is $50.4 \mathrm{~m} \times 36.0 \mathrm{~m}$. The buckling-restrained braces as hysteresis passive dampers are located in the core as indicated by dotted lines in Fig. 1. In order to simplify the model, the braces are neglected, or the stiffness of brace is replaced by additional stiffness of the beams and columns in the following examples. The location of each type of the beams and columns is specified in Fig. 1(b), where the members in the core are specified in the separate figure of the close view of the core. The cross-sectional shape for each member type is given in Table 1, where, e.g., $\mathrm{C} 1(11-31)$ indicates the column $\mathrm{C} 1$ from the 11th to 31st stories, and G13(26-32) indicates the beam G13 from the 26th to 32nd (roof) floors.

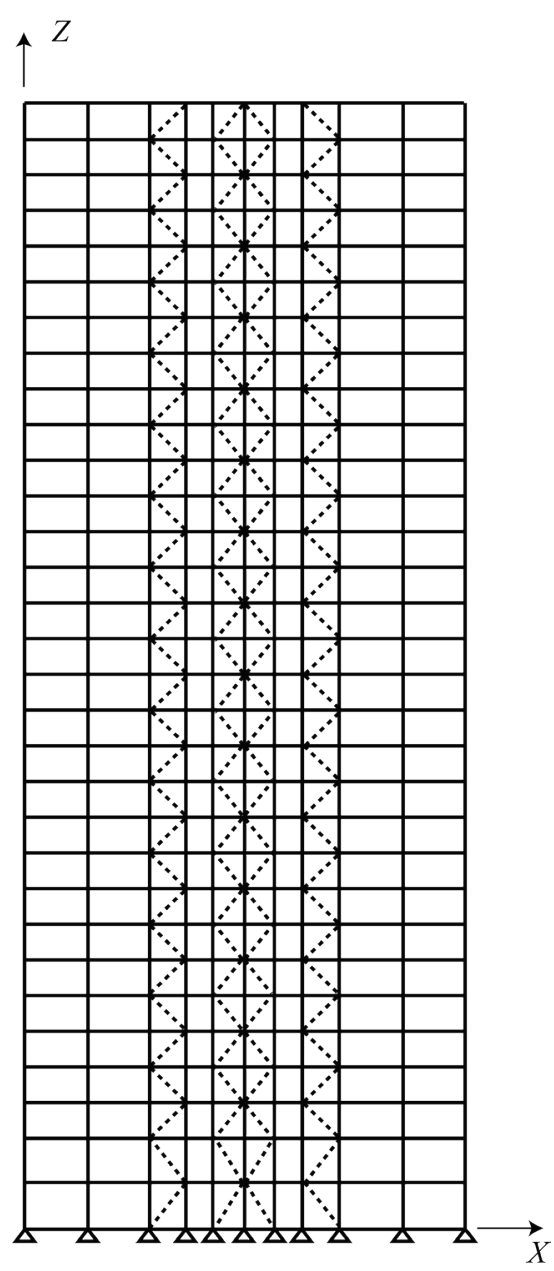

(a) elevation
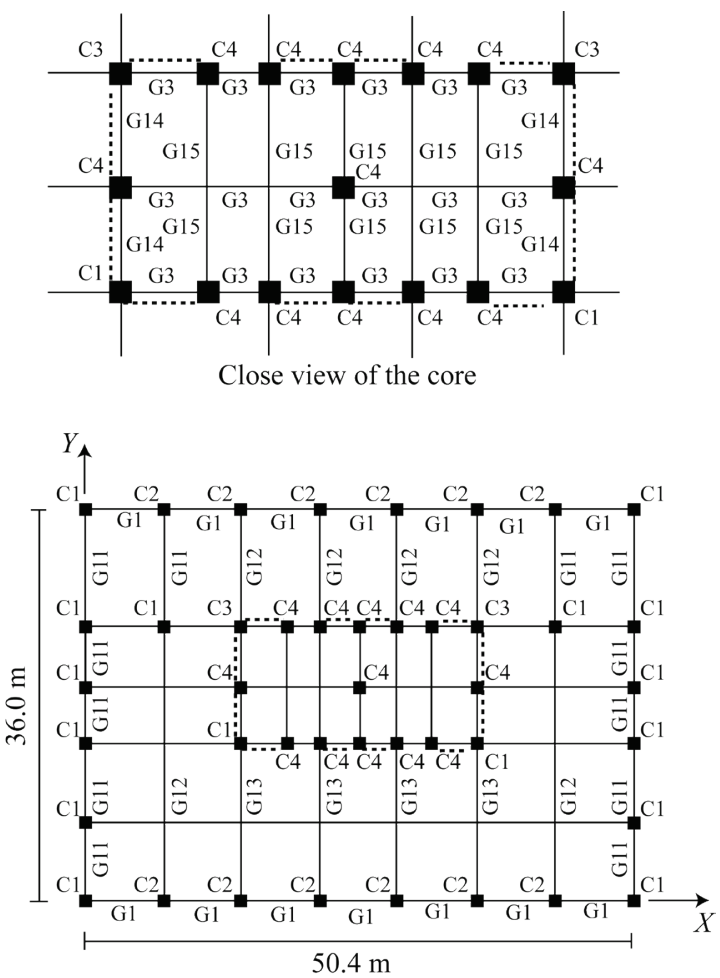

(b) plan

Figure 1. Locations of beams, columns and braces in typical vertical section and floor plan.

The materials of the frame are steel for beams and columns, and reinforced concrete for slabs. The elastic modulus, yield stress and Poisson's ratio of the steel material are 205 $\mathrm{kN} / \mathrm{mm}^{2}, 330 \mathrm{~N} / \mathrm{mm}^{2}$ and 0.3 , respectively, and isotropic hardening with coefficient $1 / 1000$ is used. The slab is also assumed to be made of elastoplastic material with isotropic hardening, where the elastic modulus is $22.7 \mathrm{kN} / \mathrm{mm}^{2}$, Poisson's ratio is 0.2 , the yield stress is $20 \mathrm{~N} / \mathrm{mm}^{2}$, and the hardening coefficient is $1 / 1000$.

The mass density of steel is $7.86 \times 10^{3} \mathrm{~kg} / \mathrm{m}^{3}$, whereas the mass density of slab is increased by the density equivalent to the floor loads as shown in Table 2 . Note that the thickness of the slab is $0.1275 \mathrm{~m}$, and the area covered by the slab is $1645.92 \mathrm{~m}^{2}$ for each floor.

The base beams are elastic and have the same sections as those in the 2 nd floor; however, 
the elastic modulus is 5.5 times as large as the standard value to represent the stiffness of the underground structure. The nodes in each column base are connected by rigid beams to a node at the center of the column, which is pin-supported.

Table 1. Member list of columns and beams.

\begin{tabular}{|c|c|}
\hline Cross-section & Member \\
\hline Box-600x600x25 & $\mathrm{C} 1(11-31), \mathrm{C} 2(16-31)$ \\
\hline Box-600x $600 \times 28$ & $\mathrm{C} 2(11-15), \mathrm{C} 3(21-31), \mathrm{C} 4(11-31)$ \\
\hline Box-650x650x32 & $\mathrm{C} 3(16-20)$ \\
\hline Box $-700 \times 700 \times 28$ & $\mathrm{C} 1(6-10), \mathrm{C} 4(1-10)$ \\
\hline Box $-700 \times 700 \times 32$ & $\mathrm{C} 2(6-10), \mathrm{C} 3(11-15)$ \\
\hline Box $-700 \times 700 \times 36$ & $\mathrm{C} 1(1-5), \mathrm{C} 2(1-5)$ \\
\hline Box $-800 \times 800 \times 36$ & $\mathrm{C} 3(6-10)$ \\
\hline Box $-800 \times 800 \times 40$ & $\mathrm{C} 3(3-5)$ \\
\hline Box-800x $800 \times 50$ & $\mathrm{C} 3(1-2)$ \\
\hline H-700x200x12×22 & G1(11-32) \\
\hline$H-700 \times 250 \times 12 \times 22$ & G11(11-32), G15(11-32) \\
\hline $\mathrm{H}-700 \times 300 \times 13 \times 24$ & $\mathrm{G} 1(2-10), \mathrm{G} 2(2-32), \mathrm{G} 11(2-10), \mathrm{G} 12(2-32)$ \\
\hline $\mathrm{H}-700 \times 300 \times 14 \times 28$ & $\mathrm{G} 13(26-32)$ \\
\hline $\mathrm{H}-700 \times 300 \times 22 \times 32$ & G13(16-25), G15(2-10) \\
\hline $\mathrm{H}-700 \times 350 \times 22 \times 28$ & G3(11-32), G14(11-32) \\
\hline $\mathrm{H}-700 \times 350 \times 22 \times 32$ & $\mathrm{G} 3(2-10), \mathrm{G} 13(2-15), \mathrm{G} 14(2-10)$ \\
\hline
\end{tabular}

Table 2. Mass density of slabs and the total floor loads except the steel beams and columns.

\begin{tabular}{lcc}
\hline Floor & Mass density $\left(\times 10^{3} \mathrm{~kg} / \mathrm{m}^{3}\right)$ & Load $(\mathrm{kN})$ \\
\hline 2 & 5.28 & 10858 \\
3 & 5.09 & 10468 \\
$4-31$ & 4.90 & 10077 \\
32 (roof) & 6.33 & 13018 \\
\hline
\end{tabular}

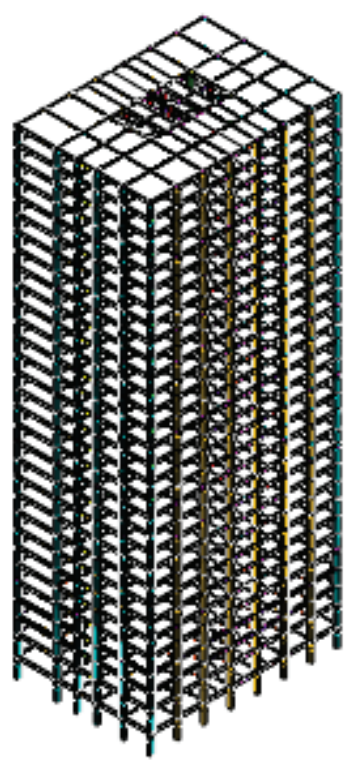

Figure 2. Three-dimensional CAD model.

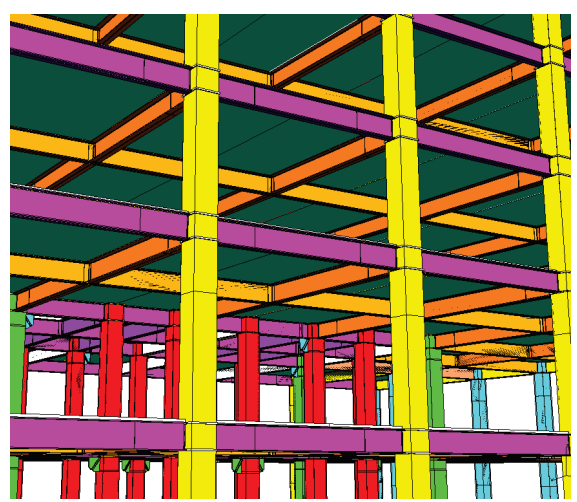

Figure 3. CAD model around the 3rd story. 


\section{THREE-DIMENSIONAL CAD MODEL AND MESH GENERATION}

Before generating FE-meshes, a three-dimensional CAD model is generated from the two-dimensional CAD model that is usually drawn in the conventional design process of steel frames. A three-dimensional solid modeler called 'I-deas' [15] is used for this purpose. A birds-eye view of the three-dimensional CAD model is shown in Fig. 2, and Fig. 3 shows the details around the 3rd story.

All the members as well as the floor slabs are modeled by 8-node hexahedral solid elements; i.e., the DOFs of each node are three translational displacements, and the displacements in the element are interpolated by tri-linear shape functions. The FE-mesh of the 1st story without base-beams is shown in Fig. 4, and Fig. 5 shows close views of the mesh around a connection. The steel plates such as the flanges and webs of beams are divided into two layers of solid elements. However, some irregular-shaped interface elements exist, as shown in Fig. 5, at the transition region of the plates with different thicknesses and in the gusset plates.

The MasterFEM package of the 'I-deas' is used for the hexahedral mesh generation. Most of the hexahedral elements are regular rectangular parallelepiped, and they are generated using the mapped mesh technique. However, the elements with irregular shape are manually generated.

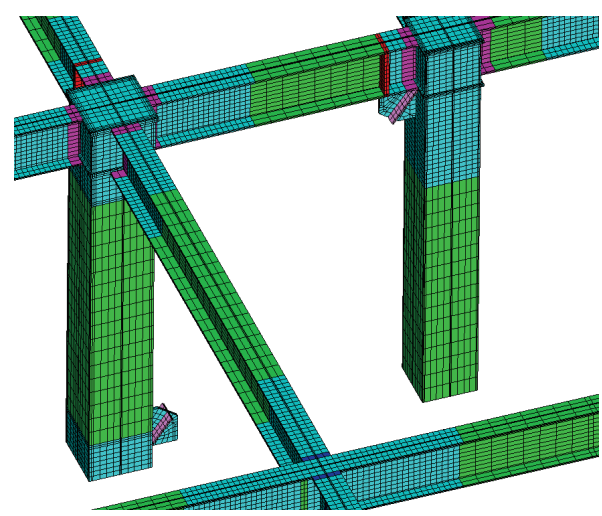

Figure 4. FE-mesh of 1st story.
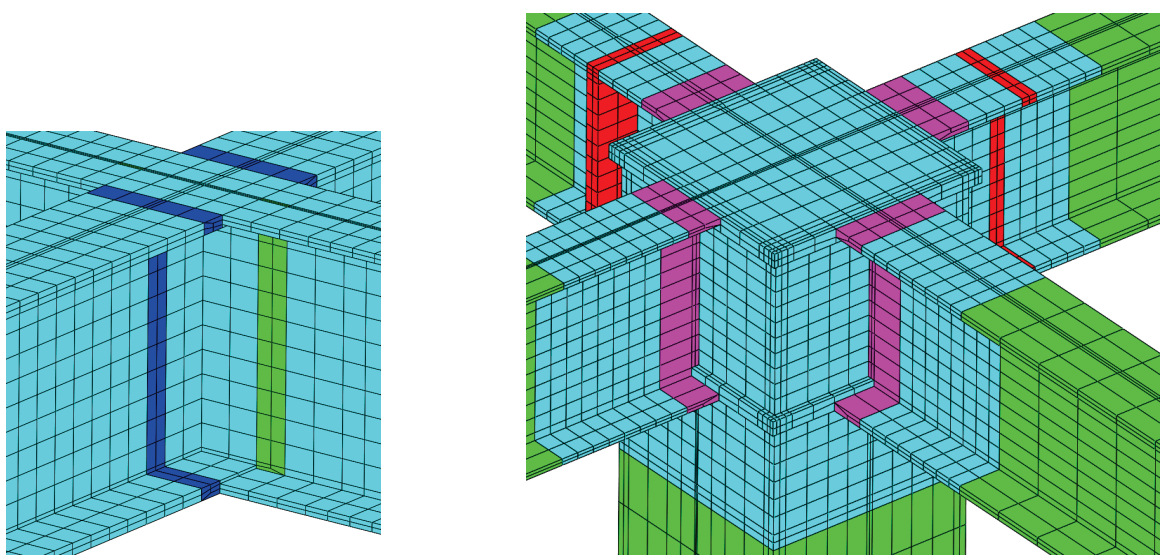

Figure 5. Close views of FE-mesh around connections.

The size of each element in the longitudinal direction of a beam or a column is approximately $70 \mathrm{~mm}$ near the connections, where severe plastic deformation is expected, while a coarser mesh is used for elements located far from the connections as shown in Figs. 4 
and 5.

Figs. 6(a) and (b) show the FE-meshes of the gusset plates and stiffeners. Although the buckling-restrained braces are not used in this study as described in the following section, FE-meshes are generated for the gusset plates for use in a future study. As shown in Fig. 7, fine mesh is also used for the slabs, which are divided into two layers. The stud that connects a slab to the flange of a beam is not accurately modeled; i.e., the lower face along boundary of the slab and the center line of the upper face of the upper flange share the same nodes. The contact between the column face and the slab is not accurately considered, and it is also modeled as shared nodes.

Arrangements of the nodes on the upper face of a story and those on the lower face of an adjacent upper story are not completely the same when thicknesses of the plates for columns are different in each story. In this case, the two stories are connected by imposing Multi-Point Constraints (MPCs) that correspond to the master-slave contact model.

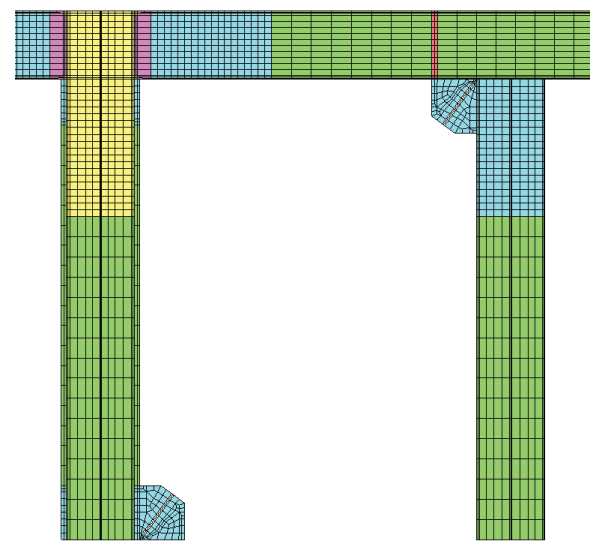

(a)

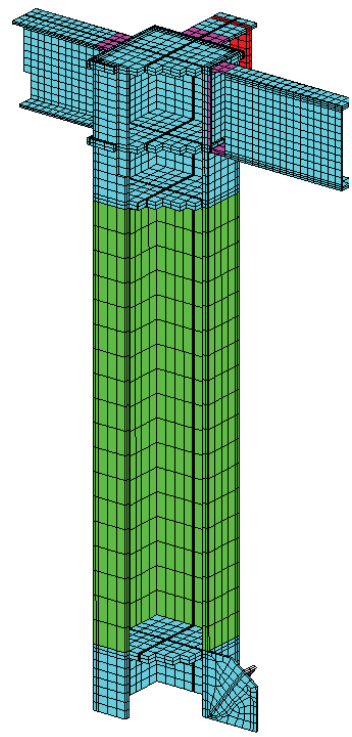

(b)

Figure 6. FE-meshes of beams, columns, gusset plates and stiffeners.

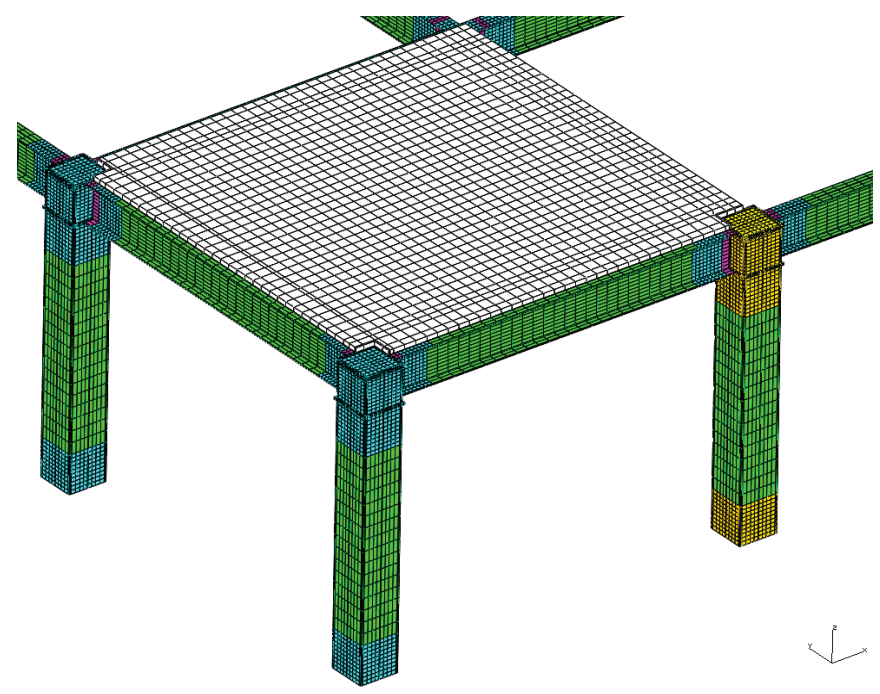

Figure 7. FE-mesh of a slab.

The process of generating FE-meshes is summarized as follows:

1. Obtain two-dimensional CAD data from the conventional design process of a steel frame. 
2. Develop three-dimensional CAD model by using 'I-deas' from the two-dimensional CAD data.

3. Generate regular rectangular parallelepiped elements using the mapped mesh generator of 'I-deas'.

4. Manually generate irregular-shaped elements near the connections, and specify the shared nodes and MPCs.

Note that the mesh is almost automatically generated if tetrahedral elements are used [16]. However, for a building frame assembled with thin plates, the required number of DOFs by tetrahedral elements will be too large to obtain the results comparable to those by hexahedral elements, because each tetrahedral element should have good aspect ratio to obtain a good result.

\section{ANALYSIS RESULTS OF STEEL FRAMES}

\subsection{Overview of analysis method}

The platform of E-simulator is ADVC [17,18], which is a commercial structural analysis code developed utilizing a framework of the public domain software ADVENTURE system $[16,19]$. ADVC has a specific solver named CGCG (Coarse Grid based Conjugate Gradient) method [17,20] that is a parallel iterative solver with a prediction based on a coarse grid motion, and is applicable to strongly nonlinear dynamic analysis [21].

The CGCG method is briefly described below for completeness of the paper. Let $\Omega$ be the target domain and $V$ be the corresponding solution space of the stiffness equation:

$$
K u=f
$$

which is equivalent to the preconditioned form:

$$
G K u=G f
$$

where $G$ is a preconditioning matrix

The standard iterative substructuring method (ISM) [22] utilizes the domain decomposition method for parallelization. The basic idea is that each decomposed subdomain is regarded as a substructure. $\Omega$ is decomposed into a number of subdomains $\Omega^{I}$, where overlap of the subdomains is not allowed and the union of $\Omega^{I}$ has to be exactly equal to $\Omega$. The subdomains are assumed to share the boundaries, which we call the inner boundary, with the neighboring subdomains. The standard ISM takes subdomains as substructures, and thereby takes each subspace $V^{I}$ corresponding to $\Omega^{I}$. This means that the standard ISM solves each substructure, normally by the direct method. The inner boundary is dealt with globally by the CG method, in which the solutions of the substructures are substituted into the equation in the inner boundary through the so-called Schur complement, or in the process of the projection from the global space to the space that corresponds to the inner boundary. However, the use of the direct method on the substructure needs a large computation cost and memory in general.

The CGCG method does not consider each subdomain as a substructure. The domain decomposition is used for parallel algorithm and for the precondition defined by the global coarse grid motion. The preconditioning matrix $G$ in Eq.(2) is constructed through defining the global coarse grid motion based on the global ridig body motion of the subdomains. Moreover, structural analysis needs algorithms that can deal with MPC for connecting different kinds of elements, for analysis of the assembled models, for contact analysis and so on. In ADVC, the subspace of the DOFs of the MPC is constructed in the global solution 
space (see for example [23]), and then the CGCG method is applied on this subspace. In dynamic analysis, an implicit integration scheme based on the Newmark- $\beta$ method is used with $\beta=0.25$, where CGCG method is applied at each time step. To build large FE-analysis models and to visualize large analysis results, the ADVC preprocessor and postprocessor are used, respectively.

In the following, we use the ADVC for elastoplastic dynamic analysis of steel frames. By making an analysis model with fine meshing, a complicated sequence of local buckling can be simulated for a steel frame. In the following examples, HP blade server BL465 equipped with 2.6GHz dual core Opteron processor and PC2-5300 DDR2 DIMM 16GB memory is used for computation. Different numbers of cores and processes are taken for the numerical examples below.

\subsection{Dynamic collapse analysis of a single-story frame}

Elastoplastic dynamic response analysis is carried out for a truncated single-story model as shown in Fig. 8 for verification of the mesh generation process and the analysis program based on ADVC. A lumped mass of $4.614 \times 10^{7} \mathrm{~kg}$ is placed as shown in Fig. 8 to represent the mass above the 2nd floor. The mass is connected to the nodes at the top of columns by the rigid beams, which is implemented as MPC, as illustrated in Fig. 8. Note that the mass is placed at the center of the core on the 2nd floor level, although it is above the 2nd floor in Fig. 8(c) for illustration purpose. The slab is not included and the column bases are fixed in this simple model, and the frame is fixed at the column bases. The numbers of elements and nodes are 520,728 and 790,265, respectively, and the number of DOFs is 2,381,712.

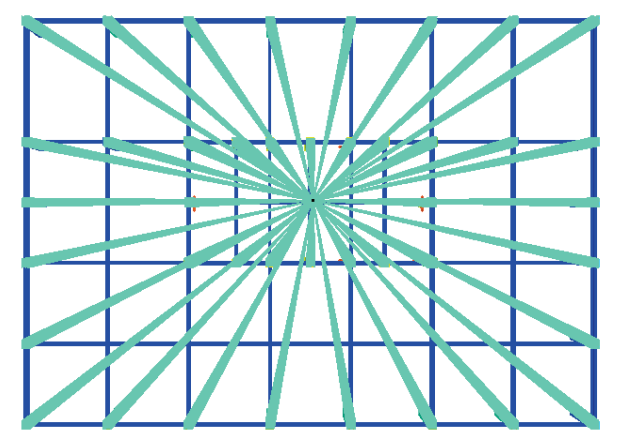

(a)

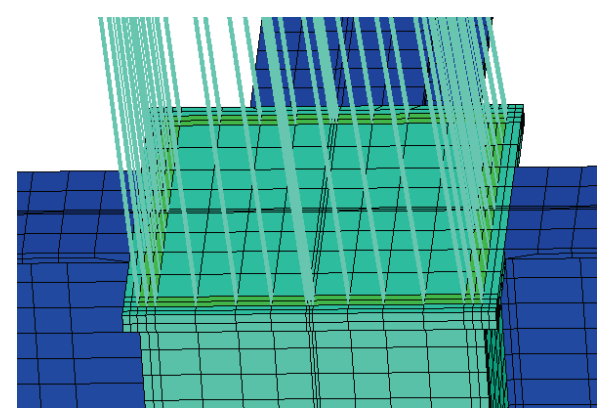

(b)

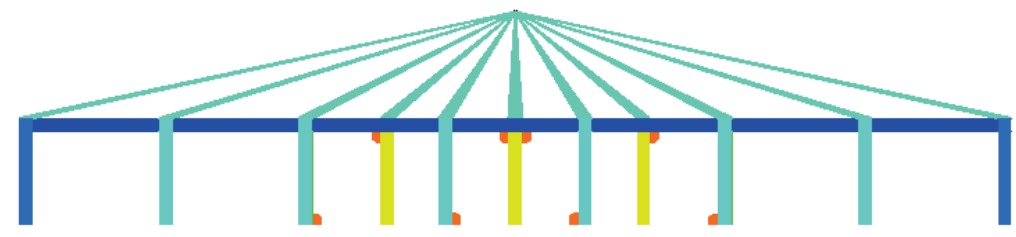

(c)

Figure 8. A single-story frame model.

A triangular wave as shown in Fig. 9(a) is used as the input acceleration in $X$-direction. The response spectra for various damping ratios are shown in Figs. 9(b)-(d). The lowest natural period of this frame is $0.6426 \mathrm{sec}$. Therefore, a large response is expected when the natural period becomes longer after plastification.

The self-weight is applied through static analysis before carrying out dynamic response analysis of duration $3.0 \mathrm{sec}$. The stiffness-proportional damping is used with damping ratio 0.02 for the 1 st mode. The tolerance of the relative error for the linear solver by CG method is $1.0 \times 10^{-4}$. The tolerance of the relative error in residual in the Newton-Raphson iteration is 0.1 . 
The time increment is $0.02 \mathrm{sec}$, which is automatically decreased if convergence of the Newton-Raphson method is not achieved. This way, only a few steps are needed for the Newton-Raphson iteration at each step of time increment, and the total elapsed time when 16 cores are used for computation is $23.9 \mathrm{hrs}$.

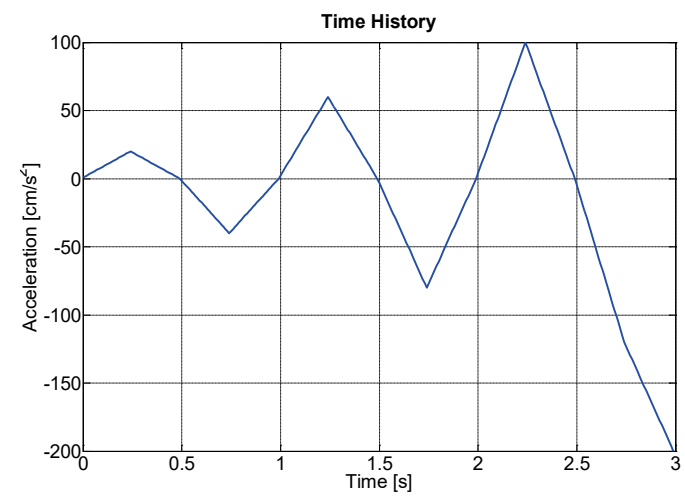

(a) time history

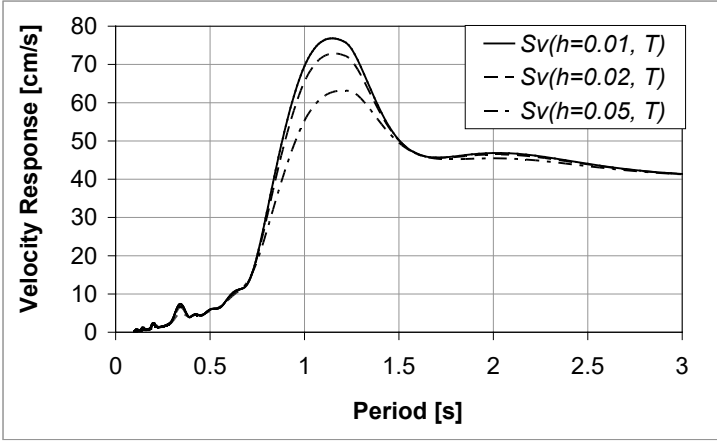

(c) velocity response spectrum

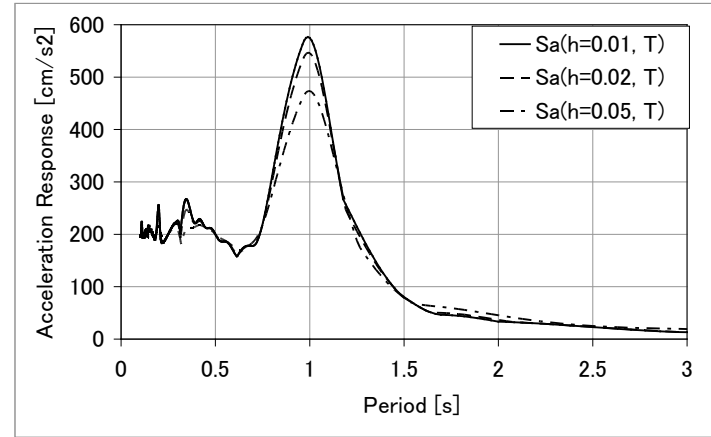

(b) acceleration response spctrum

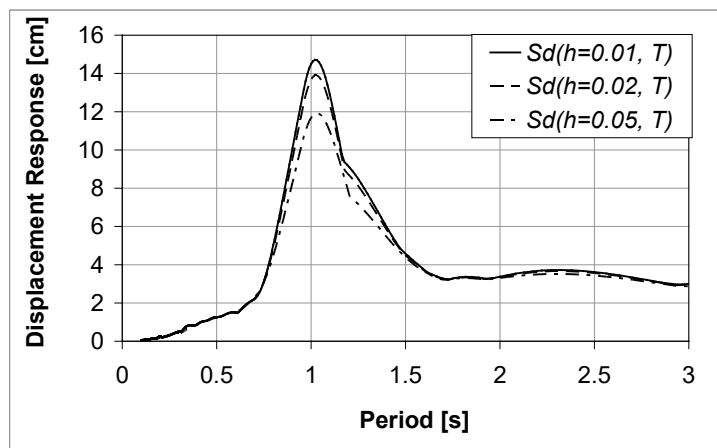

(d) displacement response spectrum

Figure 9. Time history and response spectra of the input motion for the single-story model.

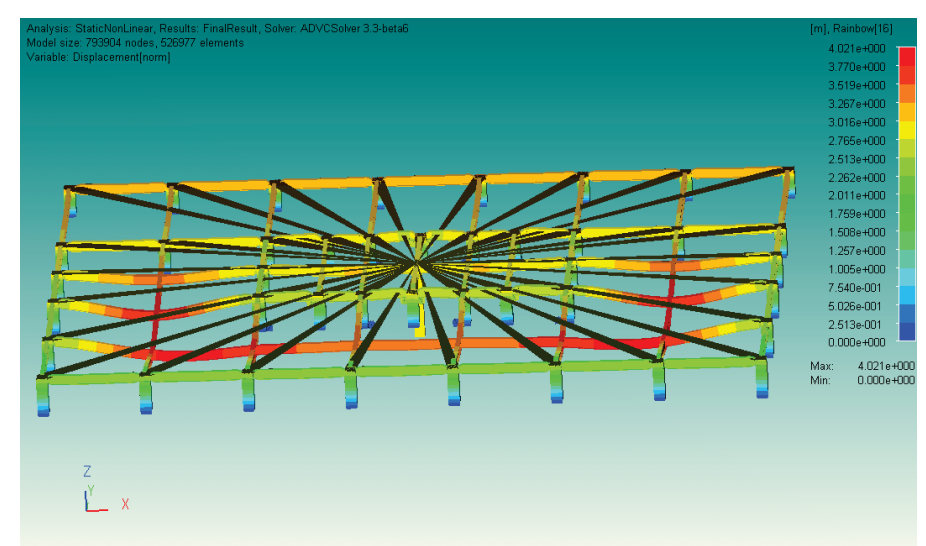

Figure 10. Distribution of norm of displacement vector of the single-story model under self-weight.

The distribution of the norm of displacement vector under self-weight is shown in Fig. 10, where the deformation is scaled by 1000 . Note that large deformation exists around the connections of the grid beams without a column at their intersection. Fig. 11 shows the distribution of von Mises stress at the time of the maximum deformation $(2.878 \mathrm{sec}$.) of 
dynamic analysis, where the deformation is scaled by 50 . Note that the stresses near the beam-to-column connections and the column bases are very large. However, the most of other parts remain in elastic range. Fig. 12 shows the local buckling of a column base, where the deformation is scaled also by 50 . This way, the collapse behavior can be successfully simulated by high-precision FE-analysis.

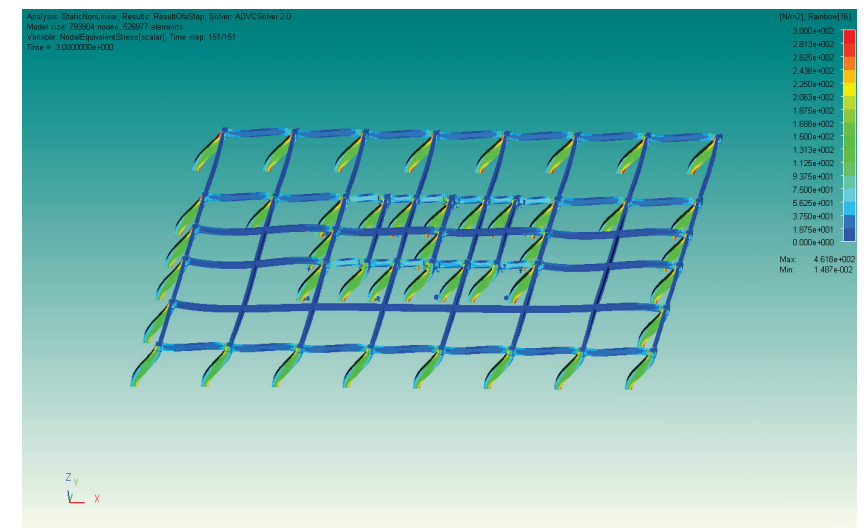

Figure 11. Distribution of von Mises stress of the single-story model at the time of maximum response under the triangular wave.

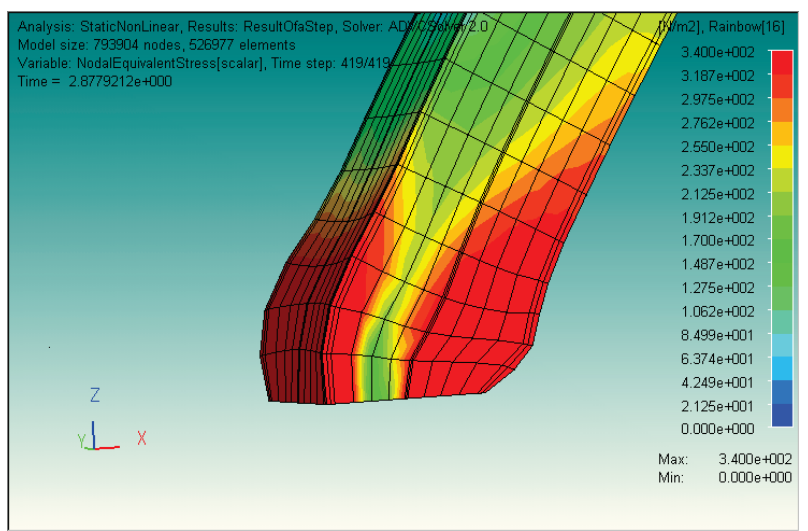

Figure 12. Local buckling at column base of the single-story model.

\subsection{Collapse analysis of a truncated 5-story frame under seismic excitation}

Elastoplastic dynamic response analysis is next carried out for a truncated 5-story frame under scaled recorded seismic motion. The frame represents the lowest five stories of the original 31 story frame model. The mass above the 6th floor is represented by a lumped mass of $3.655 \times$ $10^{7} \mathrm{~kg}$ at the center of the 23rd floor. The fine mesh in Fig. 7 is used for the concrete slabs, and the column bases are supported by base beams. The total numbers of nodes, DOFs, and elements are 4,471,144, 13,413,300, and 2,849,802, respectively. In order to incorporate the initial stiffness of the buckling-restrained braces, the elastic modulus of all the beams, columns, slabs and base-beams are two times as large as those standard values defined in Section 2. 
Table 3. Natural frequencies and periods of the 5-story model.

\begin{tabular}{ccc}
\hline Mode & Frequency $(\mathrm{Hz})$ & Period (sec.) \\
\hline 1 & 0.5369 & 1.8625 \\
2 & 0.6327 & 1.5805 \\
3 & 2.6081 & 0.3834 \\
4 & 4.5625 & 0.2192 \\
5 & 5.5357 & 0.1806 \\
6 & 5.7173 & 0.1749 \\
\hline
\end{tabular}

The six lowest natural frequencies and the corresponding natural periods are listed in Table 3, and the three lowest eigenmodes are shown in Figs. 13(a)-(c). The 1st and 2nd modes are translational vibration in $X$ - and $Y$-directions, respectively, and the 3 rd mode is a torsional mode. The elapsed time for eigenvalue analysis is $25,585 \mathrm{sec}$. with 16 cores.

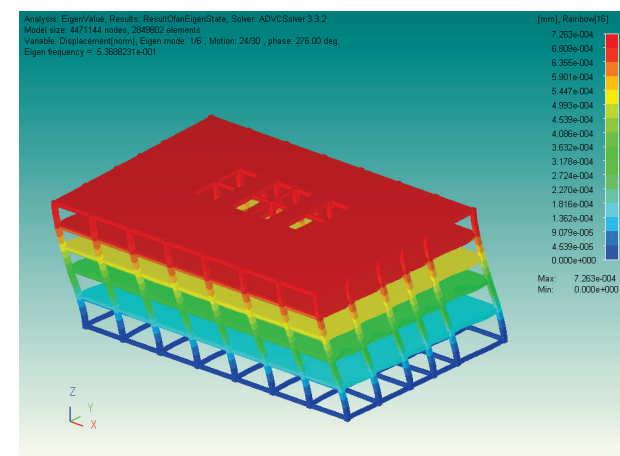

(a) mode 1

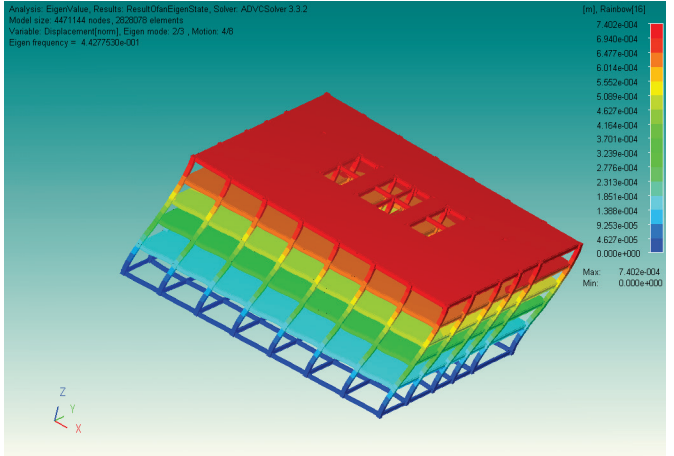

(b) mode 2

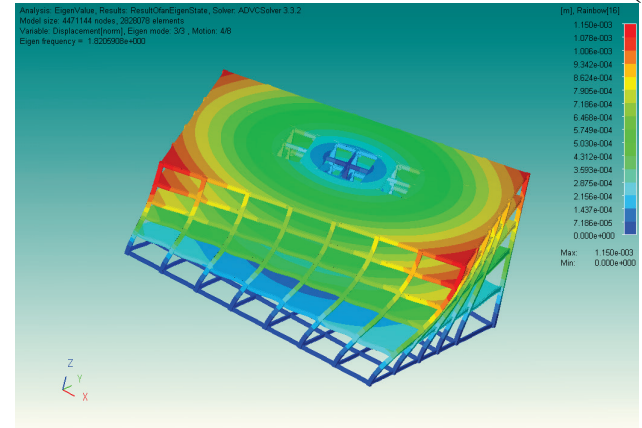

(c) mode 3

Figure 13. Three lowest eigenmodes of the 5-story model.

Dynamic collapse analysis is carried out after application of the gravity load by conducting static analysis. The input motions in $X-, Y$ - and $Z$-directions are the EW-, NS- and UD-components, respectively, of the 1995 Hyogo-ken Nanbu Earthquake Takatori wave scaled by 2.0 [24]. The time histories of the three components of the wave before scaling are as shown in Fig. 14. The forced acceleration is applied at the pin-support of each column base.

The elapsed time for one step with 32 cores is 4.99 sec.; i.e., more than 5 months will be needed for computation for the duration of 40 seconds. Fig. 15(a) shows the acceleration response spectra for the three components of the Takatori wave of full duration $(40 \mathrm{sec}$.). The response spectra for the waves of duration 5 seconds from $2 \mathrm{sec}$. to $7 \mathrm{sec}$. of the Takatori wave are also shown in Fig. 15(b). As is seen from these two figures that analysis of 5 seconds will be enough to predict the maximum response under Takatori wave. Since the fundamental natural period of the 5-story frame after plastification will be larger than $2 \mathrm{sec}$., 
and the response acceleration will be less than $1.5 \mathrm{~m} / \mathrm{s}^{2}$, the input wave of $5 \mathrm{sec}$. is scaled by 2.0 to simulate dynamic collapse behavior of the frame using an implicit integration scheme. The stiffness-proportional damping is used with damping ratio 0.02 for the 1 st mode.

The elapsed time for the analysis of 511 steps is $551.5 \mathrm{hrs}$. (23 days). Note again that the purpose of this paper is to demonstrate that local and global collapse behaviors under seismic excitations can be simulated by high-precision FE-analysis. Therefore, the details of response quantities such as maximum stress, equivalent plastic strain, etc., are not discussed in the following investigation of the analysis results.

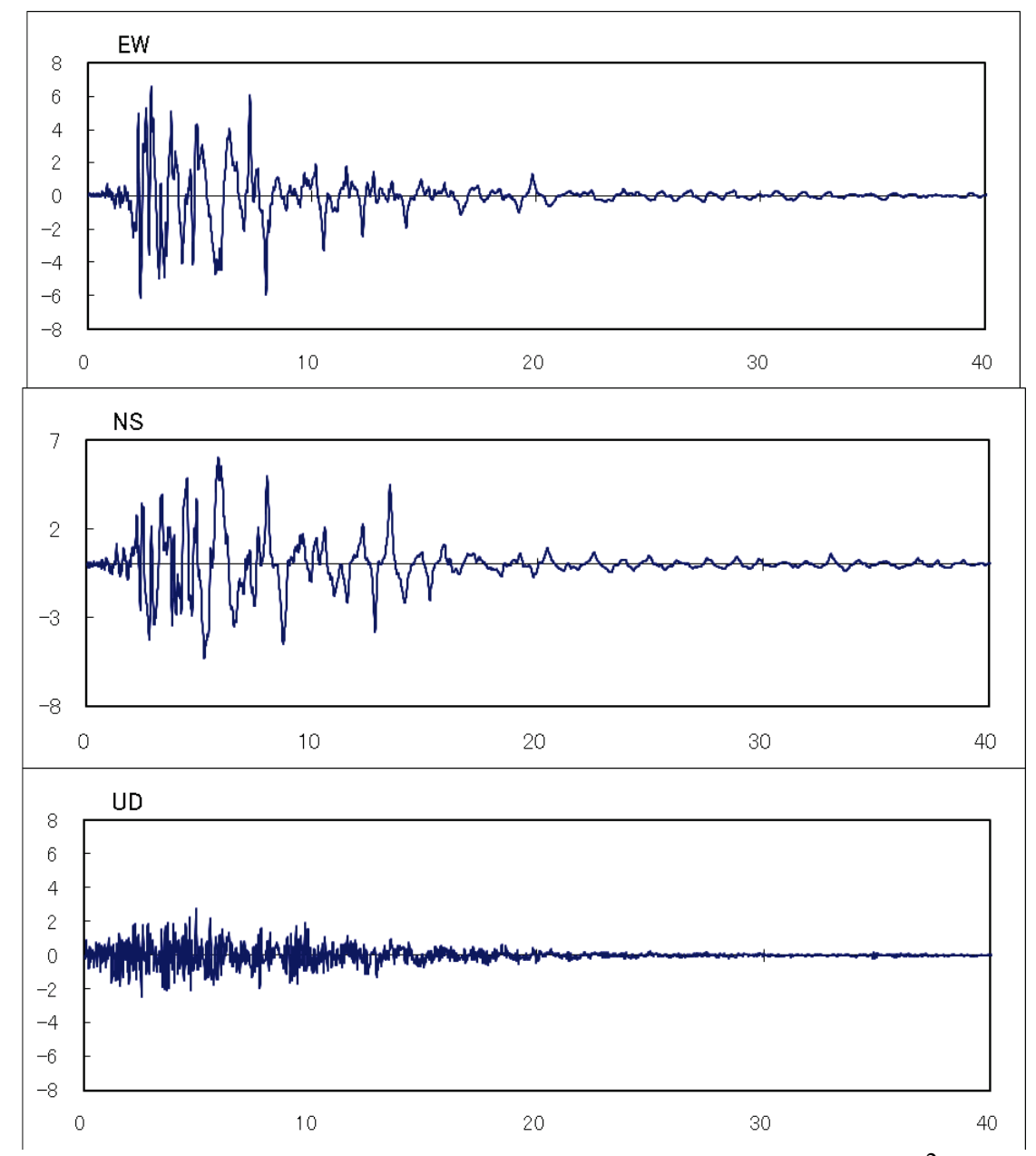

Figure 14. Time histories of the Takatori wave $\left(\mathrm{m} / \mathrm{sec}^{2}\right)$.

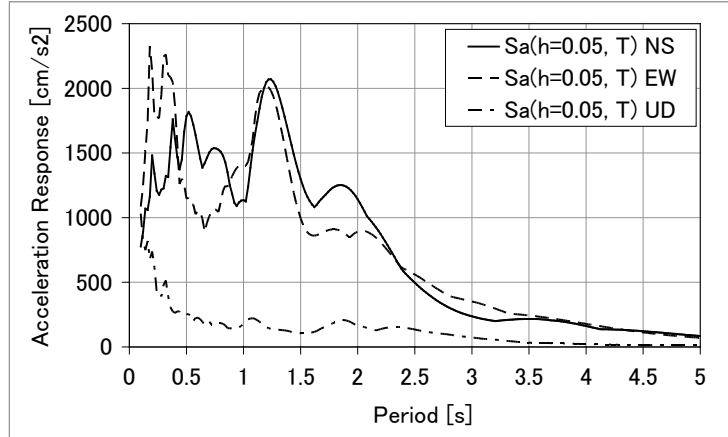

(a) duration: $40 \mathrm{sec}$.

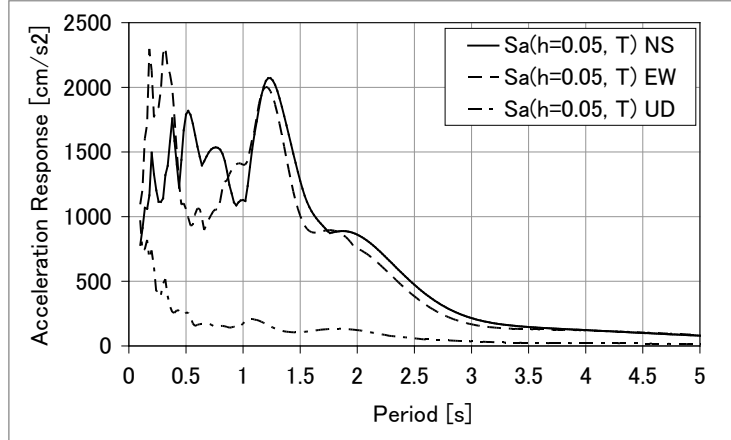

(b) duration: 5 sec.

Figure 15. Acceleration response spectra of the Takatori wave. 


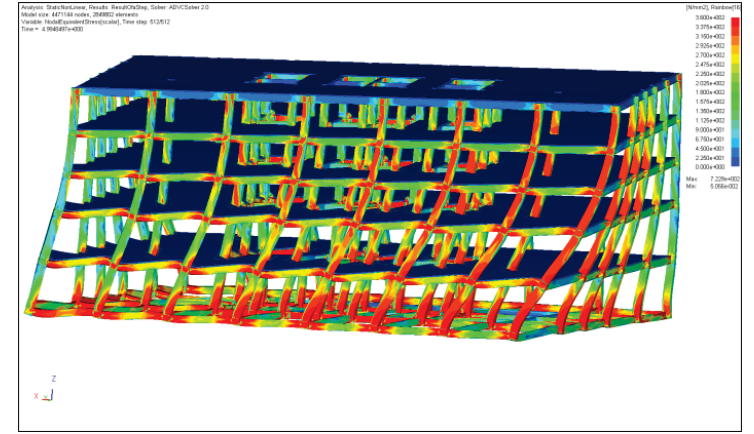

(a)

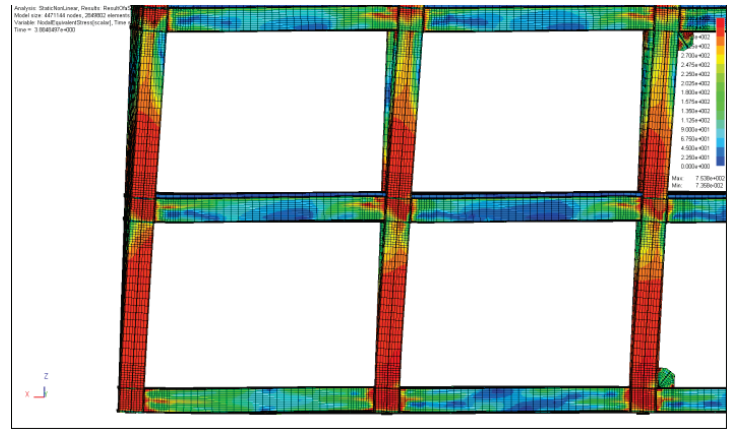

(b)

Figure 16. Distribution of von Mises stress at the maximum response of the 5-story model.

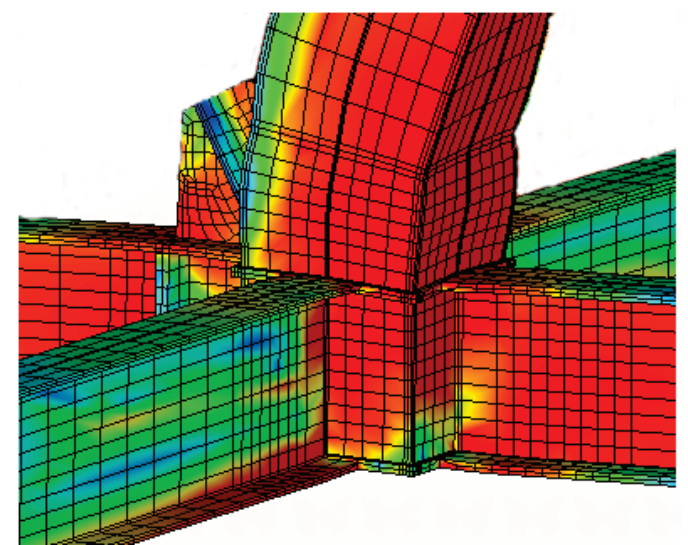

Figure 17. Deformation near the core at the maximum response of the 5-story model.

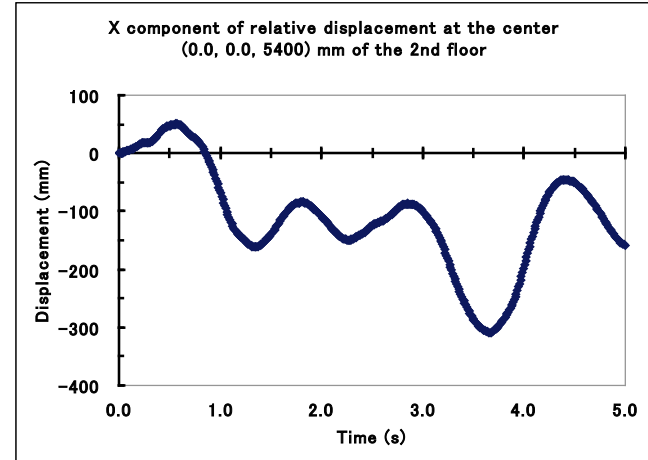

(a) $X$-direction

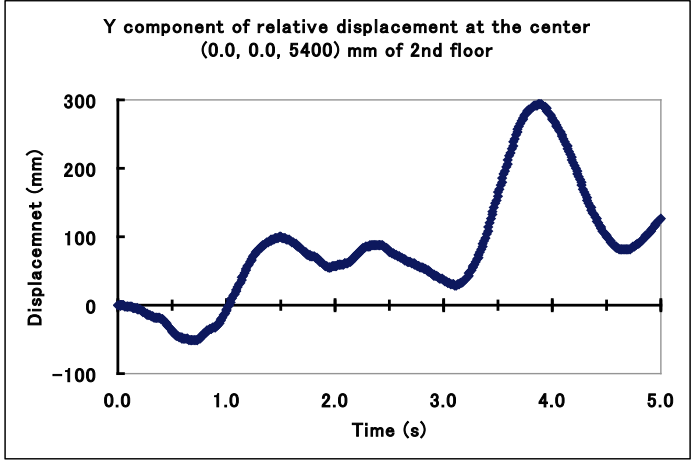

(b) $Y$-direction

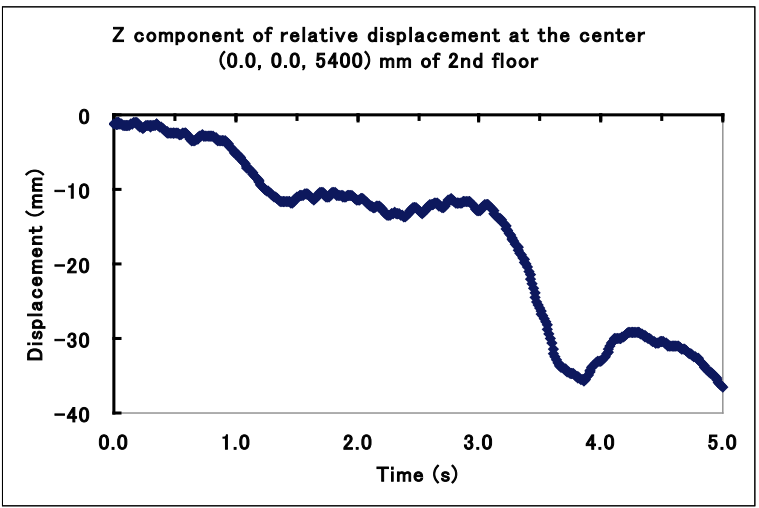

(c) Z-direction

Figure 18. Relative displacements at the center of the 2 nd floor. 
Fig. 16(a) shows the distribution of von Mises stress at the time when the maximum deformation occurs. The stress distribution in the beams and columns in lower stories is shown in Fig. 16(b). The deformation near the column base of the core is shown in Fig. 17. Note that the displacements in Figs. 16 and 17 are scaled by 10. As is seen in Fig. 17, the out-of-plane deformation near the column base has been successfully simulated. This way, the global and local elastoplastic responses can be simulated by an FE-analysis without resort to an assumption of frame behavior such as a plastic hinge model, composite beam model, degrading hysteresis mode, etc.; i.e., the collapse behavior can be simulated based only on the standard elastoplastic constitutive models of materials considered at each integration point in each solid element.

Fig. 18 shows the time-histories of relative displacements in three directions at the center of the 2 nd floor. The maximum $Y$-directional relative displacement is $300 \mathrm{~mm}$. Since the story height is $5400 \mathrm{~mm}$, the maximum interstory drift angle is $0.056 \mathrm{rad}$., which is large enough to induce local buckling.

\subsection{Eigenvalue analysis of a 31-story frame}

Eigenvalue analysis is carried out for the 31-story frame model shown in Fig. 1. To reduce the cost of mesh generation, the properties between the 11th and 31 st stories, where no significant plastification is expected, are assumed to be the same as those of the 10th story. However, the elastic modulus is modified to approximate the original model in Fig. 1. Furthermore, the elastic modulus of beams, columns, slabs and base-beams are scaled by 2.0 to consider the initial stiffness of the braces. The numbers of elements, nodes, and DOFs are 15,635,158, $24,783,633$, and $74,350,770$, respectively.

Table 4. Natural frequencies and periods of the 31-story model.

\begin{tabular}{ccc}
\hline Mode & Frequency $(\mathrm{Hz})$ & Period (sec.) \\
\hline 1 & 0.3704 & 2.6998 \\
2 & 0.4235 & 2.3613 \\
3 & 0.4596 & 2.1758 \\
4 & 1.1035 & 0.9062 \\
5 & 1.2346 & 0.8100 \\
6 & 1.3392 & 0.7467 \\
\hline
\end{tabular}

The six lowest natural frequencies and periods are listed in Table 4, and the corresponding eigenmodes are shown in Fig. 19. The natural periods of the 31-story model are larger than those of the 5-story model. The elapsed time for eigenvalue analysis is $92,087 \mathrm{sec}$. $(25.6 \mathrm{hrs}$.) with 32 cores. The 1 st mode is a translational vibration in $Y$-direction, and the 2 nd and $3 \mathrm{rd}$ modes are the mixture of torsion and $X$-directional translation. This way, eigenvalue analysis has been successfully carried out for the high-resolution FE-model. Obviously, the three-dimensional torsional vibration cannot be detected by the conventional method of dynamic analysis of lumped-mass model. Therefore, it is important that the dynamic properties of a super-highrise building frame should be investigated based on a model that can incorporate the three-dimensional effects. 


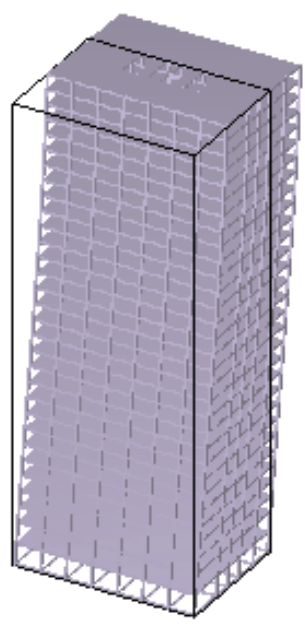

(a) $1 \mathrm{st}$

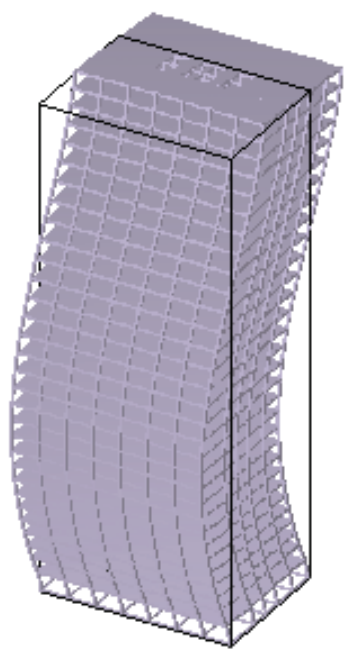

(d) 4 th

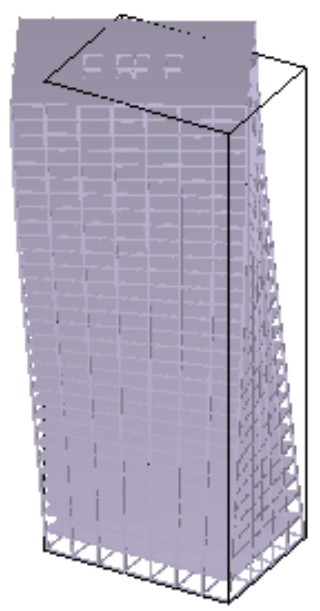

(b) 2 nd

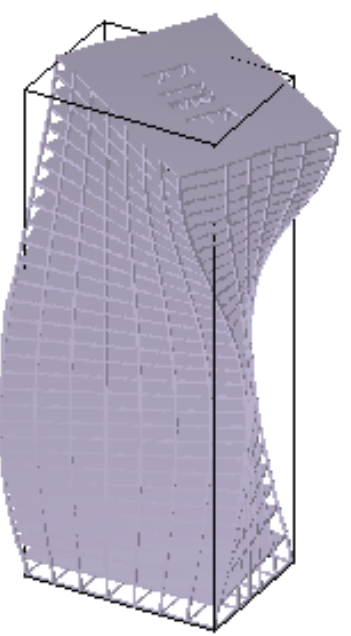

(e) 5 th

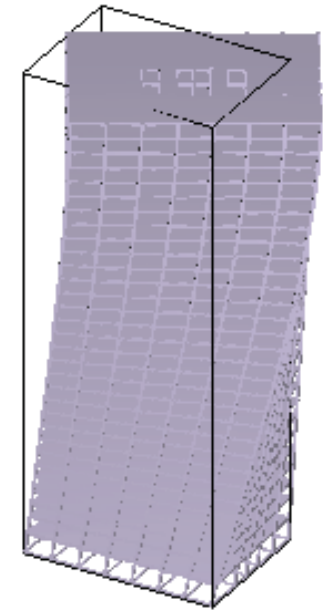

(c) 3rd

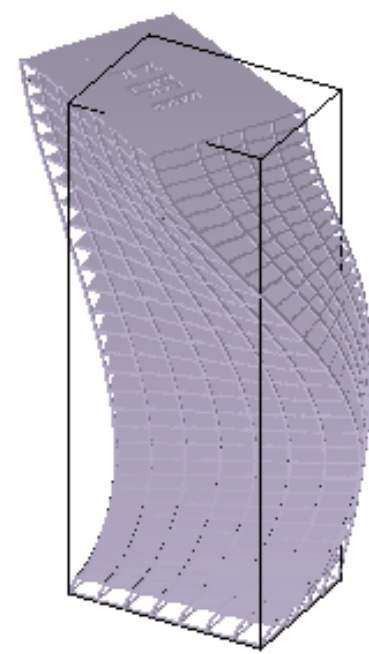

(f) 6 th

Figure 19. Eigenmodes of the 31-story frame model.

\section{CONCLUSIONS}

A general-purpose parallel FE-analysis software based on the domain decomposition method, which is a platform of the E-Simulator, has been applied to simulation of dynamic collapse behavior of large-scale steel frames. For verification purpose of the mesh generation and analysis software, elastoplastic dynamic analysis was carried out only for the truncated single-story and the 5-story models without buckling-restrained braces, and eigenvalue analysis was carried out for the 31-story frame.

It has been shown in the numerical examples that out-of-plane local buckling can be successfully simulated using the high-precision FE-model. This way, the local elastoplastic responses can be simulated by FE-analysis without resort to an assumption of frame behavior such as plastic hinge model, composite beam model, degrading hysteresis mode, etc.; i.e., the global and local responses of a large-scale frame model can be simulated by simple constitutive model and fine FE-meshes.

Currently, it takes too much effort to generate fine FE-meshes, because the meshes around the connections should be generate manually. Therefore, it is necessary to develop a particular mesh generator of steel frames to provide researchers with high-precision FE-analysis 
environment that can replace physical shaking-table test.

\section{ACKNOWLEDGEMENTS}

This study is a part of E-Defense Seismic Experimental Study and Simulation System Construction Project conducted by E-Simulator Production Committee (Leader: Hirohisa Noguch, Keio University). The authors acknoweledge the valuable contribution from the committee members, and the financial support by the National Research Institute for Earth Science and Disaster Prevention. The contribution by Dr. Onda and Dr. Yuyama of Allied Engineering Corporation for computation and mesh generation is also acknoweledged.

\section{REFERENCES}

1. Hori M, Noguchi H, Ine T. Project report of development of numerical shaking table coping with E-Defense, JSCE Journal of Earthquake Engineering 2007; 29:1420-1425. (in Japanese)

2. Hyogo Earthquake Engineering Research Center (E-Defense), http://www.bosai.go.jp/hyogo/ehyogo/index.html

3. Tada M, Ohsaki M, Yamada S, Motoyui S, Kasai K. E-Defense tests on full-scale steel buildings: Part 3 - Analytical simulation of collapse, Proc. Structures Congress 2007, ASCE, Long Beach, 2007.

4. Ohsaki M, Kasai K, Matsuoka Y, Zhang JY. Results of recent E-Defense tests on full-scale steel buildings: Part 2 - Collapse simulation and blind analysis contest, Proc. Structures Congress 2008, ASCE, Vancouver, 2008.

5. Charmpis DC, Papadrakakis M. Improving the computational efficiency in finite element analysis of shells with uncertain properties, Computer Methods in Applied Mechanics and Engineering 2005; 194:1447-1478.

6. Challa VRM, Hall JF. Earthquake collapse analysis of steel frames, Earthquake Engineering and Structural Dynamics, 1994; 23:1199-1218.

7. Isobe D, Lynn KM. Aircraft impact analysis of World Trade Center Tower by using ASI-Gauss technique, Journal of Structural and Constructional Engineering, Architectural Institute of Japan, 2006; 600:83-88.

8. Lynn KM, Isobe D. Finite element code for impact collapse problems of framed structures, International Journal for Numerical Methods in Engineering 2007; 69(12):2538-2563.

9. Kaewkulchai G, Williamson EB. Beam element formulation and solution procedure for dynamic progressive collapse analysis, Computers \& Structures, 2004; 82:639-651.

10. Khandelwal K, El-Tawil S, Sadek F. Progressive collapse analysis of seismically designed steel braced frames, Journal of Constructional Steel Research, 2008; published online, doi:10.1016/j.jcsr.2008.02.007

11. Villaverde R. Methods to assess the seismic collapse capacity of building structures: State of the art, Journal of Structural Engineering, ASCE, 2007; 133(1):57-66.

12. Tagawa H, Gurel S, Application of steel channels as stiffeners in bolted moment connections, Journal of Constructional Steel Research 2005; 61:1650-1671. 
13. Pan $\mathrm{P}$, Ohsaki M, Tagawa $\mathrm{H}$. Shape optimization of H-beam flange for maximum plastic energy dissipation, Journal of Structural Engineering, ASCE, 2007; 133(8):1176-1179.

14. Tsai KC, Chou CC, Lin CL, Chen PC, Jhang SJ. Seismic self-centering steel beam-to-column moment connections using bolted friction devices, Earthquake Engngineering and Structural Dynamics 2007; 37:627-645.

15. UGS Corp., I-deas User's Guide, 2006.

16. ADVENTURE project website, http://adventure.q.t.u-tokyo.ac.jp/

17. Akiba $\mathrm{H}$ et al., Large scale drop impact analysis of mobile phone using ADVC on Blue Gene/L, Proc. International Conference for High Performance Computing Networking and Storage (SC06), Tampa, 2006.

18. Ogino M, Shioya R, Kawai H, Yoshimura S. Seismic response analysis of nuclear pressure vessel model with ADVENTRUE System on the Earth Simulator, Journal of The Earth Simulator 2005; 2:41-54.

19. Yoshimura S, Shioya R, Noguchi H, Miyamura T. Advanced general-purpose computational mechanics system for large scale analysis and design, Journal of Computational and Applied Mathematics 2002; 149:279-296.

20. Suzuki M, Ohyama T, Akiba H, Yoshimura S, Noguchi H. Development of fast and robust parallel CGCG solver for large scale finite element analyses, Transactions of the Japan Society of Mechanical Engineers, Series A, 2002; 68:1010-1017. (in Japanese)

21. Yoshimura S, Ino M, Akiba H, Makino H. Full scale nonlinear burst simulation of pipeline containing high-pressure multi-component natural gas, Proc. 9th US National Congress on Computational Mechanics, 2007.

22. Smith B, Bjørstad P, Gropp W, Domain Decomposition: Parallel Multilevel Methods for Elliptic Partial Differential Equations, Cambridge University Press, 1996.

23. Miyamura $T$. Incorporation of multipoint constraints into the balancing domain decomposition method and its parallel implementation, International Journal for Numerical Methods in Engineering 2007; 69:326-346.

24. Nakamura Y, Uehan F, Inoue H. Waveform and its analysis of the 1995 Hyogo-Ken-Nanbu Earthquake information, Report No. 23d, Railway Technical Research Institute, 1995. (in Japanese). 